\title{
Nanostructured biosensor using bioluminescence quenching technique for glucose detection
}

\author{
Longyan Chen', Longyi Chen ${ }^{1}$, Michelle Dotzert ${ }^{2}$, C. W. James Melling ${ }^{2}$ and Jin Zhang ${ }^{1 *}$ (1)
}

\begin{abstract}
Background: Most methods for monitoring glucose level require an external energy source which may limit their application, particularly in vivo test. Bioluminescence technique offers an alternative way to provide emission light without external energy source by using bioluminescent proteins found from firefly or marine vertebrates and invertebrates. For quick and non-invasive detection of glucose, we herein developed a nanostructured biosensor by applying the bioluminescence technique.

Results: Luciferase bioluminescence protein (Rluc) is conjugated with $\beta$-cyclodextrin ( $\beta$-CD). The bioluminescence intensity of Rluc can be quenched by $8 \pm 3 \mathrm{~nm}$ gold nanoparticles (Au NPs) when Au NPs covalently bind to $\beta$-CD. In the presence of glucose, Au NPs are replaced and leave far from Rluc through a competitive reaction, which results in the restored bioluminescence intensity of Rluc. A linear relationship is observed between the restored bioluminescence intensity and the logarithmic glucose concentration in the range of 1-100 $\mu \mathrm{M}$. In addition, the selectivity of this designed sensor has been evaluated. The performance of the senor for determination of the concentration of glucose in the blood of diabetic rats is studied for comparison with that of the concentration of glucose in aqueous.
\end{abstract}

Conclusions: This study demonstrates the design of a bioluminescence sensor for quickly detecting the concentration of glucose sensitively.

Keywords: Bioluminescence, Biosensor, Nanoparticles, Glucose

\section{Background}

Glucose is one of the most important carbohydrates to provide energy for cell metabolism. Studies also show that glycolytic flux is closely related to enzyme levels. Control of glucose level is the key to the regulation of signaling protein-involved pathways, and to manage chronic diseases, e.g. diabetics [1]. Different techniques from electrochemical methods to fluorescence detections have been developed for monitoring glucose level in vitro and in vivo [2-4]. Biosensors by using luminescence techniques have advantages in directly converting bioprocess to luminescence signal through a non-toxic

\footnotetext{
*Correspondence: jzhang@eng.uwo.ca

${ }^{1}$ Department of Chemical and Biochemical Engineering, University of Western Ontario, 1151 Richmond St., London, ON N6A 5B9, Canada Full list of author information is available at the end of the article
}

and cost-effective process [5]. Resonance energy transfer (RET) techniques including Förster/fluorescence RET (FRET) and bioluminescence RET (BRET) are distancedependent non-radiation energy transfer, which have been used for detecting protein-protein interactions in vitro and in vivo [6-8].

Generally, both FRET and BRET utilize the resonance energy transfer from a fluorophore donor to a fluorophore acceptor. The resonance energy transfer is dependent on the distance between donor and acceptor. Recent developments on FRET biosensor unveil a quenching mechanism due to the resonance energy transfer between metallic nanoparticles (NPs) and fluorophore donor. The quenching mechanism allows luminescence biosensor to obtain high signal-to-noise ratio, in which the fluorescence intensity of the donor can be quenched by the acceptor made of metallic nanoparticles, and the 
fluorescence intensity of the donor can be restored if the distance between the donor and metallic NPs increases $[9,10]$. Metallic NPs, e.g. gold nanoparticles (Au NPs), can be used as an acceptor to quench the fluorescence of a donor in a FRET sensor due to their large extinction coefficients and broad energy absorption in the visible range. The quenching efficiency is reverse proportional to the distance between nanoparticle and the donor in a designed FRET biosensor [11-13]. The FRET assays by using quenching mechanism have been applied in different organic-based assays for nucleic acid detection [14, 15].

Bioluminescence is a unique phenomenon in nature which can be found from firefly to marine vertebrates and invertebrates. Currently, bioluminescence techniques have been used in studying gene expression. BRET technique shows an advantage over FRET technique because it does not require the external energy, e.g. light source, to excite the donor. Therefore, BRET technique has been used for real-time and non-invasive detection [16, 17]. Normally, bioluminescence reaction happens when luciferase, an enzyme, reacts with the substrate, e.g. coelenterazine (CTZ) $[18,19]$. Luciferase protein can be used as a donner in BRET biosensor [20,21]. Quite recently, luciferase protein conjugated onto Au NP has been demonstrated for proteases detection [16]. The bioluminescence intensity of luciferase can be eliminated/quenched by the conjugated Au NPs through the resonance energy transfer process. To our best knowledge, no such system has been applied in detection of analytes other than proteases.

Here, we developed a bioluminescence sensor by applying bioluminescent quenching principle for detecting glucose in a homogeneous assay format. The nanostructured biosensor is composed of a donor, i.e. Renilla luciferase conjugated with $\beta$-cyclodextrin ( $\beta$-CD-Rluc), and a quenching element made of Au NPs modified with phenylboronic acid (PBA) as shown in Scheme 1. It is known that PBA can react with glucose by forming cyclic ester $[22,23]$. PBA has been used as a recognition element for glucose sensing $[24,25]$. Once Au NPs modified with PBA react with $\beta$-CD-Rluc through a reversely covalent bond as shown in Scheme 1, Au NPs can quench the bioluminescence intensity generated by Rluc reacting with coelenterazine (CTZ). In the presence of glucose, the bioluminescence intensity will be restored due to the stronger interaction between glucose and PBA, which leads to the release of $\beta$-CD-Rlu from PBA-Au NPs. In this study, we have investigated the effect of the ratio of the donor to the quenching on the optimal bioluminescence intensity with/without glucose. The study demonstrates the restored bioluminescence intensity as a function of the concentration of glucose.

\section{Methods}

Renilla reniformis luciferase gene (Rluc) was purchased from Promega Inc. The vector pET-32a (EMD Millipore Inc.) was used to subclone the Rluc. The E. coli strain BL21 (DE3) (invitrogen) was used as the bacterial strain for the expression of proteins. Restriction enzymes were purchase from New England Biolabs Inc. Unless otherwise indicated, all the chemicals were purchased from Sigma-Aldrich. Ultrahigh quality water with a resistance of $18.2 \mathrm{M} \Omega \mathrm{cm}$ (at $25^{\circ} \mathrm{C}$ ) was obtained from a Nanopure $^{\mathrm{TM}}$ water system (Thermofisher) fitted with a $0.22 \mu \mathrm{M}$ filter.

\section{Preparation of Au NP-based acceptor of the BRET sensor}

Citrate-stabilized gold nanoparticles (Au NPs) were synthesized by using the reported method [26]. In brief, $240 \mathrm{~mL}$ of aqueous solution containing $0.21 \mathrm{mM}$ of $\mathrm{HAuCl}_{4}(0.08 \mathrm{mg} / \mathrm{mL})$ and trisodium citrate $(13.8 \mathrm{mg})$ was mixed at room temperature. The mixture was added $5 \mathrm{~mL}$ of ice-cold $0.1 \mathrm{M} \mathrm{NaBH}_{4}$ solution under vigorous stirring. The solution was aged overnight in a dark place with vigorous stirring. Citrate-stabilized Au NPs were further modified by 11-mercaptoundecanoic acid (MUA). $20 \mathrm{~mL}$ of citrate-stabilized Au NPs $(60 \mathrm{nM}, \mathrm{pH}$ pre-adjusted to 10.3 by $2 \mathrm{M} \mathrm{NaOH}$ ) was mixed with $19 \mathrm{~mL}$ of ethanol. $1 \mathrm{~mL}$ of MUA $(10 \mathrm{mM})$ ethanol solution was added in the gold solution and stirred for $19 \mathrm{~h}$ (hrs). The mixture was then filtered through $0.45 \mu \mathrm{m}$ acetate filter and purified by Amicon ultralfilter $(100 \mathrm{kDa}$ MWCO). Finally, the MUA modified particles were resuspended in $20 \mathrm{~mL}$ water $(\sim 60 \mathrm{nM})$.

MUA-modifying $\mathrm{Au}$ NPs (MUA-Au NPs) was further conjugated with 3-aminophenylboronic acid (PBA) through carbodiimide reaction. Briefly, MUA-Au NPs $(60 \mathrm{nM})$ was mixed with PBA $(10 \mathrm{mg} / \mathrm{mL})$, 1-ethyl-3-(3dimethylaminopropyl)-carbodiimide (EDC, $10 \mathrm{mg} / \mathrm{mL}$ ), and $n$-hydroxysuccinimide (NHS, $10 \mathrm{mg} / \mathrm{mL}$ ) for $2 \mathrm{~h}$ at room temperature with gently shaking. The conjugated particles were further purified by Amicon ultrafilter (MWCO $100 \mathrm{kDa}$ ) and resuspended in phosphate-buffered saline buffer (PBS, $10 \mathrm{mM}, \mathrm{pH}$ 7.4).

\section{Preparation of Rluc protein}

The entire coding sequences of Rluc was cloned to the MCS site of pET 32-a plasmid under two restriction sites (BamH I and Xho I). Two primers were designed for the cloning (forward: 5'AAAGGATCCAGCGGTGGTG GTGGTAGCATGACTTCGAAAGTTTATGATCCAG; reverse: $5^{\prime}$ TGTGCTCGAGTTGTTCATTTTTGAGA ACTCGCTC $3^{\prime}$ ). A trx region from pET 32-a coding for thioredoxin protein is kept to maintain high level of recombinant protein expression [27]. A six-amino acid linker (SGGGGS) highlighted by the underline in the 


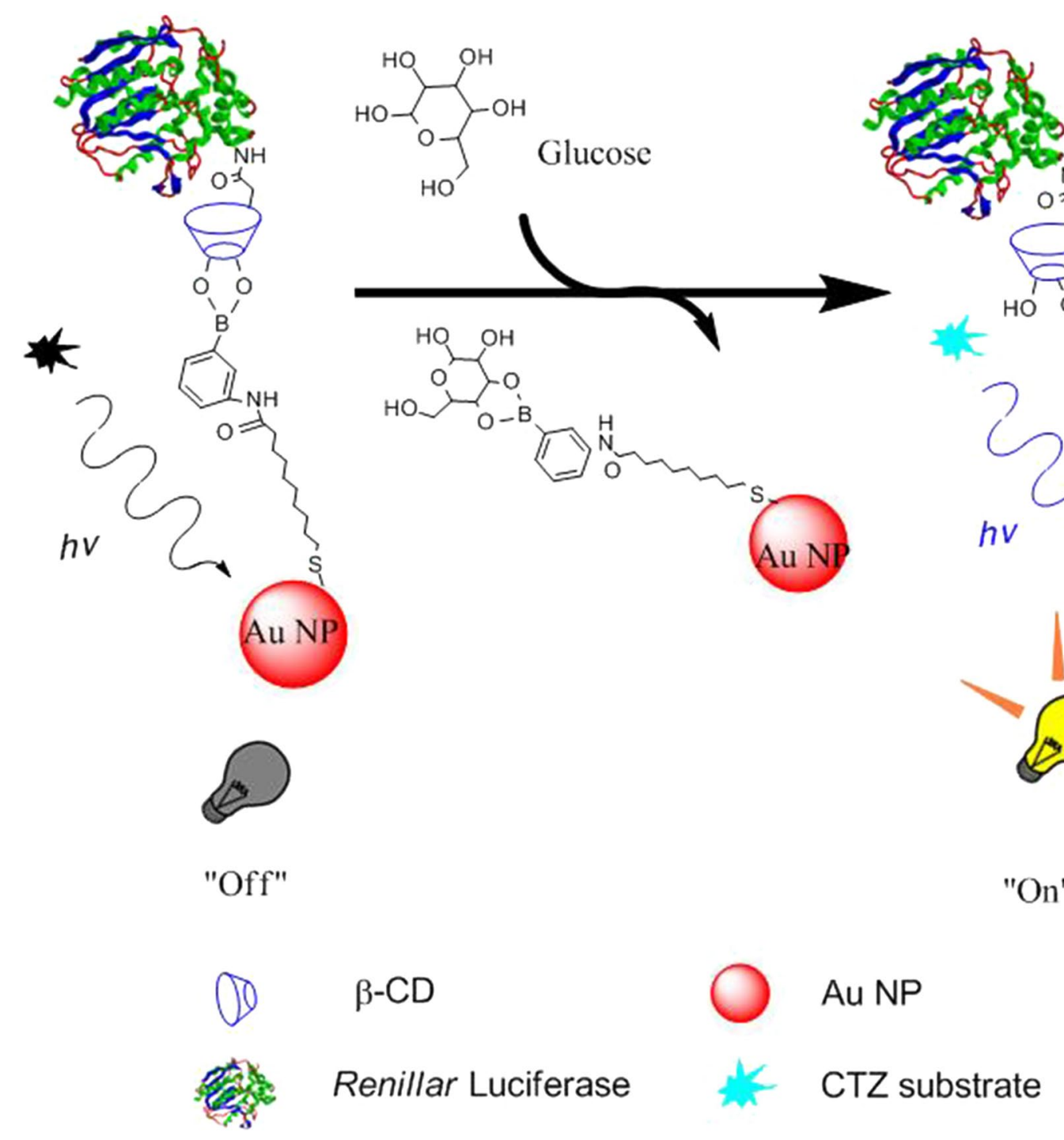

Scheme 1 Schematic illustration of bioluminescence quenching-based nanosensor in glucose sensing

forward primer was inserted after BamH I site to leave a flexible space for proper folding of Rluc protein. The successful construction of the plasmid was confirmed by DNA sequencing (Robarts Institute, Western University, London, ON).

For protein expression, the bacterial cells (E. coli $\mathrm{k}-12)$ with recombinant plasmid were grown from a single colony overnight at $37^{\circ} \mathrm{C}$ in $5 \mathrm{~mL}$ of Luria-Bertani (LB) broth (containing $100 \mu \mathrm{g} / \mathrm{mL}$ ampicillin). After transferring to $500 \mathrm{~mL}$ of LB broth, the cells were allowed growing for $2 \mathrm{~h}$ at $37{ }^{\circ} \mathrm{C}$. The cells were then cultured with isopropyl $\beta$-D-1-thiogalactopyranoside (IPTG) at a final concentration of $1 \mathrm{mM}$ for $4 \mathrm{~h}$ at $20{ }^{\circ} \mathrm{C}$. The cells were harvested by centrifugation at $12,000 \mathrm{rpm}$ for $5 \mathrm{~min}$ at $4{ }^{\circ} \mathrm{C}$, and the pellet was resuspended in a lysis buffer [20 mM Tris/HCl buffer ( $\mathrm{pH}$ 7.4), containing $500 \mathrm{mM}$ $\mathrm{NaCl}, 5 \mathrm{mM}$ imidazole, $0.2 \mathrm{mg} / \mathrm{mL}$ of lysozyme and $0.1 \%$ Triton-X-100] and sonicated with ice cooling for $15 \mathrm{~s}$ (s) followed by 30-s rest for 20 cycles by a Mandel Scientific Q500 sonicator. The suspension was centrifuged at $10,000 \mathrm{rpm}$ at $4{ }^{\circ} \mathrm{C}$ for $30 \mathrm{~min}$. The supernatant containing overexpression protein was purified via His-trap HP columns (GE lifescience, Inc.) by a syringe pump. After loading the samples, the expressed protein was eluted with an elution buffer [ $200 \mathrm{mM}$ imidazole, $20 \mathrm{mM}$ Tris/ $\mathrm{HCl}$ buffer (pH 7.4), $500 \mathrm{mM} \mathrm{NaCl}$ and $10 \%$ glycerol] and dialyzed with PBS using Pur-A-Lyzer ${ }^{\mathrm{TM}}$ Mega Dialysis Kit (12KDa MWCO, Sigma-Aldrich). The purified protein 
was further concentrated by an Amicon Ultra centrifugal filter (ultra-15, MWCO $10 \mathrm{kDa}$, EMD Millipore Inc). The resultant Rluc protein solution was stored in aliquot at $-80^{\circ} \mathrm{C}$. The concentration of the protein was determined by bicinchoninic acid (BCA) protein assay (Thermo scientific Inc).

\section{Conjugation of $\beta$-cyclodextrin ( $\beta-C D$ ) to Rluc}

Dimethylformamide (DMF) solution containing $3.78 \mathrm{mg}$ of succinyl- $\beta$-cyclodextrin $(\sim 2 \mu \mathrm{mol})$ was mixed with $250 \mu \mathrm{L}$ of $10 \mathrm{mg} / \mathrm{mL}$ NHS and $400 \mu \mathrm{L}$ of $16 \mathrm{mg} / \mathrm{mL}$ EDC. The mixture in $350 \mu \mathrm{L}$ PBS was incubated for $2 \mathrm{~h}$ at room temperature under gently shaking. For conjugating reaction, $200 \mu \mathrm{L}$ of above solution was mixed with $200 \mu \mathrm{L}$ of $10 \mathrm{mg} / \mathrm{mL}$ Rluc solution in a PBS solution (final volume was maintained at $1 \mathrm{~mL}$ ). The solution was further incubated overnight at $4{ }^{\circ} \mathrm{C}$. The reaction was terminated by addition of $5 \mu \mathrm{L}$ of ethanolamine. The $\beta$-CD labeled Rluc ( $\beta$-CD-Rluc) was purified through a Nap-10 column (GE Healthcare) with PBS as an eluent. The labeled protein was collected by Amicon ultral filter (ultra-15) to desired concentration and stored at $4{ }^{\circ} \mathrm{C}$ for at least 4 weeks which can maintain over $90 \%$ activity. For long-term storage, the labeled protein was stored at $-80{ }^{\circ} \mathrm{C}$ with complete retention of activity.

\section{Carbohydrate assay}

The amount of $\beta-C D$ modified on a Rluc was determined by a sulfuric acid-phenol assay with slight modification [18]. The detailed results can be found from the supporting documents. In a typical test, a $30 \mu \mathrm{L}$ of ice-colded glucose standard samples or $\beta$-CD-Rluc solution was mixed with $100 \mu \mathrm{L}$ of concentrated sulfuric acid in microplate wells. $20 \mu \mathrm{L}$ of aqueous $5 \%$ phenol solution was then added into the well. The plate was floated uncovered on near boiling $\left(>90^{\circ} \mathrm{C}\right)$ water bath for $5 \mathrm{~min}$ for color development, followed by cooling on ice for another $5 \mathrm{~min}$. A microplate reader (Tecan M200 multimode microplate reader) was used to collect the absorbance of each well at $490 \mathrm{~nm}$. The concentration of standard solution was plotted with the absorbance of each solution. The molar concentration of $\beta-C D$ was thus calculated. The number of $\beta$-CD per protein was obtained by dividing the molar concentration of $\beta$-CD over the molar concentration of protein Rluc.

Evaluation of the bioluminescence quenching-based assay $3 \mu \mathrm{L}$ of $\beta$-CD-Rluc $(1 \mu \mathrm{M})$ was mixed with $100 \mu \mathrm{L}$ of PBA-Au NPs (30 nM) in a PBS solution containing $0.1 \%$ bovine serum albumin (BSA). BSA was added to stabilize Rluc activity and reduce non-specific binding between protein and Au NPs. $10 \mu \mathrm{L}$ of glucose solution (with different concentrations) was added in the above solution.
For the reactivity assay, $10 \mu \mathrm{L}$ of all the tested substances with concentration of $50 \mu \mathrm{M}$ was added into the above solution. The final incubation volume was $300 \mu \mathrm{L}$. The solution was then incubated at room temperature for $30 \mathrm{~min}$. The bioluminescence was then collected by adding $1 \mu \mathrm{L}$ of native coelenterazine $(\mathrm{CTZ}, 1 \mathrm{mg} / \mathrm{mL}$ in ethanol) in the above solution.

Male Sprague-Dawley rats, 8-weeks of age, were obtained from Charles River Laboratories. Rats were housed two per cage at constant temperature and humidity on a $12 \mathrm{~h}$ dark/light cycle, and had access to water and standard chow ad libitum. Ethics approval was obtained from the University of Western Ontario Research Ethics Board, in accordance with Canadian Council on Animal Care guidelines. The experimental protocol followed the Principles of Laboratory Animal Care (US NH publication No83-85, revised 1985). Diabetes was induced with multiple low-dose Streptozotocin (STZ) injections. STZ (20 mg/kg; Sigma Aldrich, Oakville, ON, Canada) in citrate buffer was injected into the intraperitoneal cavity for 5 consecutive days, and the blood samples of diabetic rats were measured by glucometer to verify the glucose concentration is larger than $20 \mathrm{mM}$. Diluted blood samples of diabetic rats with varied glucose concentrations, i.e. $100,50,20,10,5$ and $1 \mu \mathrm{M}$, were prepared for evaluating the performance of the nanostructured sensor.

\section{Materials characterization}

$\mathrm{Au}$ nanoparticles with different surface modification were characterized by transmission electron microscope (TEM), UV-Vis spectrometer, and Fourier transform infrared spectroscopy (FTIR).

Transmission electron microscopy (TEM) image was obtained through a Philips CM-10 operating at $100 \mathrm{kV}$. Dynamic light scattering (DLS) measurements were performed on a Zetasizer Nano-ZS (Malvern Instruments Inc.) equipped with a $\mathrm{He} / \mathrm{Ne}$ laser at $633 \mathrm{~nm}$. UV-Vis spectroscopic measurements were obtained on a Cary 300 spectrometer. Fourier transform infrared (FT-IR) spectra were conducted within the $4000-500 \mathrm{~cm}^{-1}$ wavenumber range using a Bruker FTIR-IFS 55 spectrometry. Bioluminescence measurements were recorded by using a QuantaMaster 40 Spectrofluorometer (Photon Technology International Inc., London, ON). The software was set up at emission collection. The shutter at laser path was closed and the emission spectra were collected from 430 to $580 \mathrm{~nm}$ in a mode of $2 \mathrm{~nm}$ per step and integration time at $0.2 \mathrm{~s}$.

\section{Results}

Carboxyl-modified $\beta$-CD was conjugated onto Rluc protein through the carbodiimide-mediated reaction, Native polyacrylamide gel electrophoresis (native-PAGE) was 
used to investigate the conjugation of carboxyl-modified $\beta$-CD to Rluc. It is noted that the $\beta$-CD conjugation could decrease protein positive charges because of the formation of primary amine group. Hence, the proteins with or without the conjugation of $\beta-C D$ could be separated by native-PAGE on basis of protein surface charges [17]. In Fig. 1, the sample of $\beta$-CD-Rluc (lane 2) displays significant band shift as compared to the negative control, i.e. Rluc without conjugation (lane 1). Meanwhile, the conjugation of $\beta-C D$ onto Rluc protein was evaluated by using sulfuric acid-phenol colorimetric assay for total carbohydrate after purification $[18,19]$. In Additional file 1 :

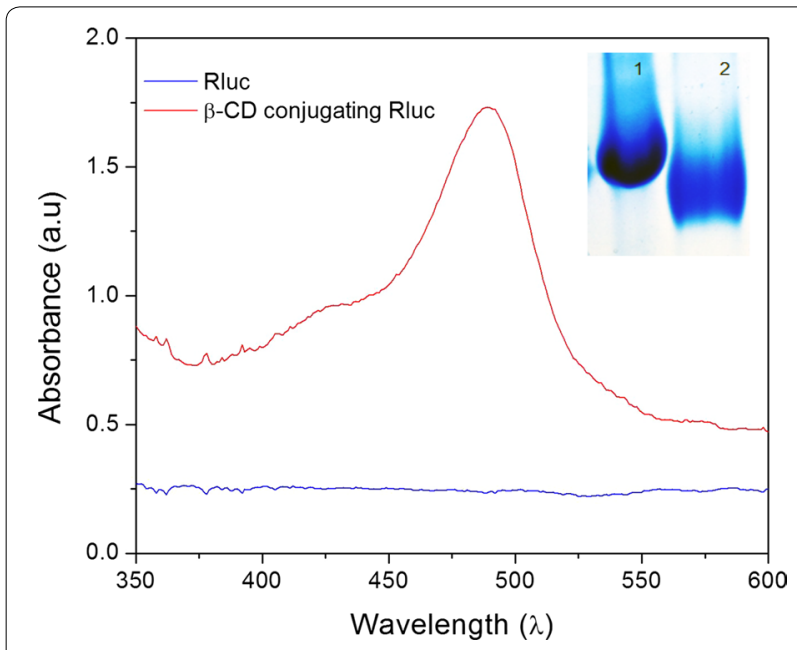

Fig. 1 UV-vis spectra of the Rluc with/without the conjugation of $\beta$-CD. The small inset image is the native-PAGE characterization, where Lane 1 is Rluc without conjugation, and Lane 2 refers $\beta-C D$ conjugating-Rluc
Figure S1, the typical peak at $490 \mathrm{~nm}$ to the sample of $\beta-C D$ conjugating Rluc is observed, which confirms the successful conjugation of $\beta$-CD to the protein. The optimized molar ratio of $\beta-C D$ to Rluc protein is estimated at $100: 1$, that is, $10 \beta$-CD molecules on each Rluc molecule, which is determined through the standard curve (Additional file 1: Figure S1, ESI + ). The precipitation of protein is observed when the molar ratio of $\beta-C D$ to Rluc is larger than 100:1, which might be related to the high co-solvent (dimethylformamide) concentration in buffer [28]. TEM and DLS were carried out to measure the average particle size and size distribution of Au NPs. Figure $2 \mathrm{a}$ is the TEM micrograph of Au NPs. The spherical NPs have the average particle size around $8 \pm 3 \mathrm{~nm}$. While, the result of DLS indicates that average particle size is around $10 \mathrm{~nm}$ with large size distribution as shown in Fig. 2b. In addition, Fig. 3a shows the UV-Vis spectra of Au NPs with different modification. The citrate-stabilized Au NPs have typical surface plasmon resonance peak at $512 \mathrm{~nm}$. The localized surface plasmon resonance (LSPR) of $\mathrm{Au}$ NP with the modification of MUA and PBA is centering at 525 and $550 \mathrm{~nm}$, respectively. The broaden absorption band could be related to the changes in the local environment and chemical interface dampening [29]. The surface modifications on Au NPs was further investigated by FTIR spectra. In Fig. 3b, the peaks around $1344 \mathrm{~cm}^{-1}$ (to $1362 \mathrm{~cm}^{-1}$ ) are attributed to B-O stretch from PBA [30]. Phenyl ring signature bands are observed at $1427 \mathrm{~cm}^{-1}$ (strong) and $1604 \mathrm{~cm}^{-1}$ (weak) to PBA-Au NPs [22]. The $\mathrm{N}-\mathrm{H}$ bending band (red dash circle in Fig. $2 \mathrm{~b}$ ) is shown at $1581 \mathrm{~cm}^{-1}$, which appears relative weak peak to the sample of PBA-Au NPs [25]. The amide I band of PBA-Au NPs associated with $-\mathrm{C}=\mathrm{O}$ stretch of peptide bond spans
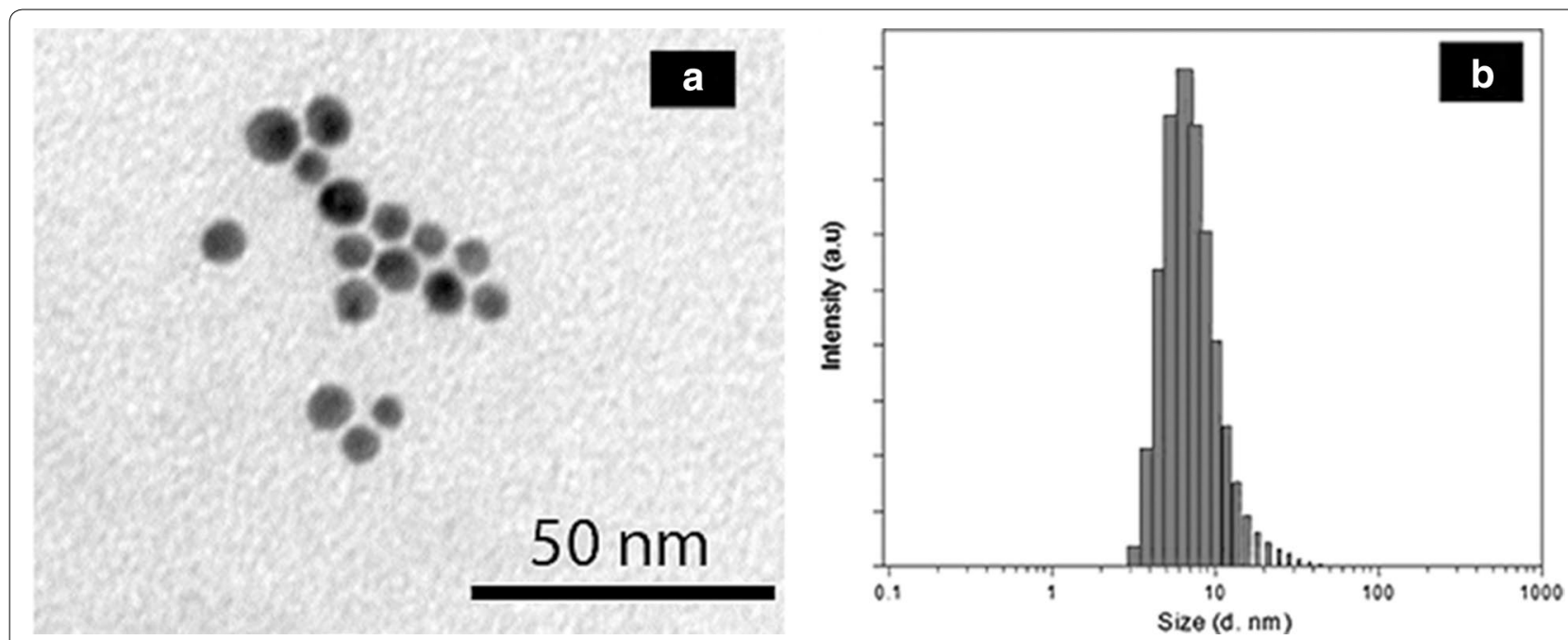

Fig. 2 a TEM micrograph of citrate acid capped Au NPs; and $\mathbf{b}$ DLS analysis of the citrate acid capped Au NPs 


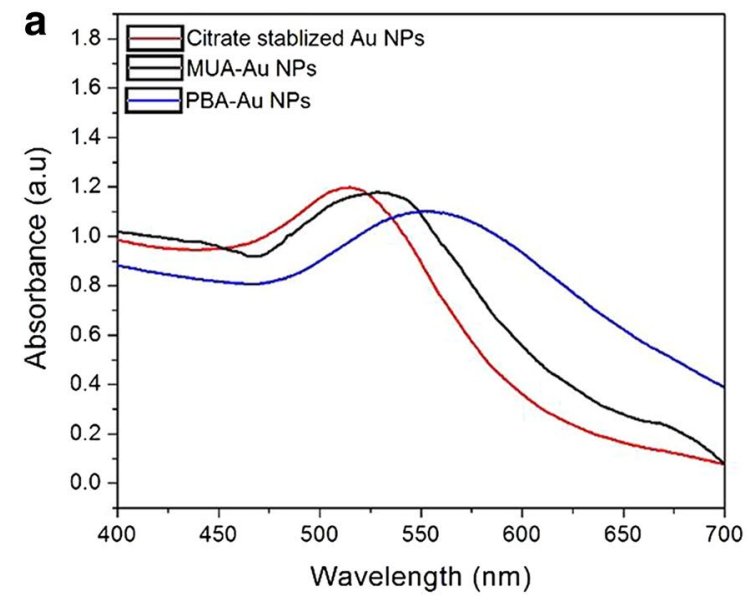

b

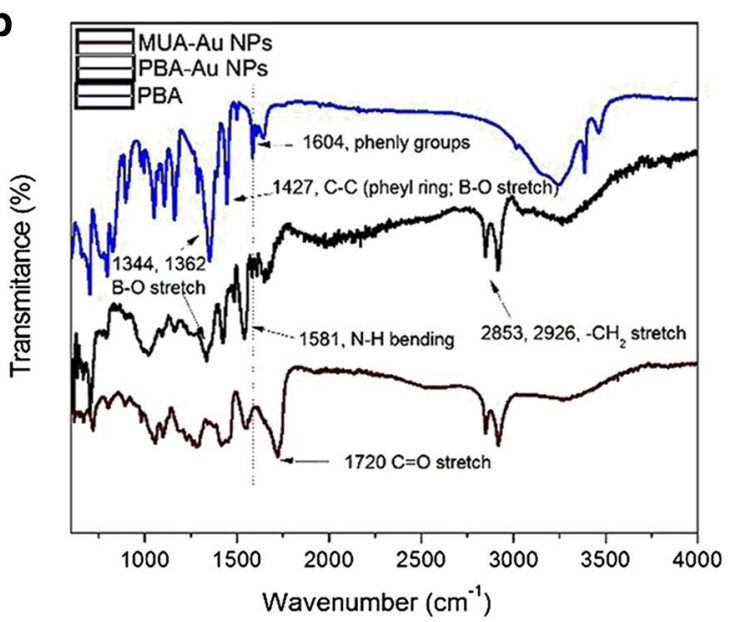

Fig. 3 Characterization of the acceptor of the BRET sensor. $\mathbf{a}$ UV-vis spectra of Au nanoparticles with surface modifications. b FTIR spectra of Au NPs with surface modifications

from 1600 to $1700 \mathrm{~cm}^{-1}$ [31]. The results of FTIR indicates that successful modification of Au NPs with PBA.

PBA-Au NPs then react with $\beta$-CD-Rluc through the reversible boronic acid-diol interaction [22]. The interaction between PBA-Au NPs and $\beta$-CD-Rluc was investigated by agarose gel electrophoresis. In Fig. $4 \mathrm{a}$, the mixture of PBA-Au NPs and $\beta$-CD-Rluc displays the slowest migrating band (lane 2 ) as compared to the negative controls, i.e. PBA-Au NPs alone (lane 1), PBA-Au NPs mixing with unmodified Rluc (lane 3), and MUA-Au NPs alone (lane 4). This band shift could be attributed to an increase of NPs in terms of particle size, due to the formation of $\beta$-CD-Rluc/PBA-Au NP complex. Without $\beta$-CD conjugation, Rluc/PBA-Au NP mixture shows similar band position to PBA-Au NP. Thereby, the interaction of conjugated protein with PBA-Au NP is specific due to the boronic acid-diol interaction. The bioluminescence

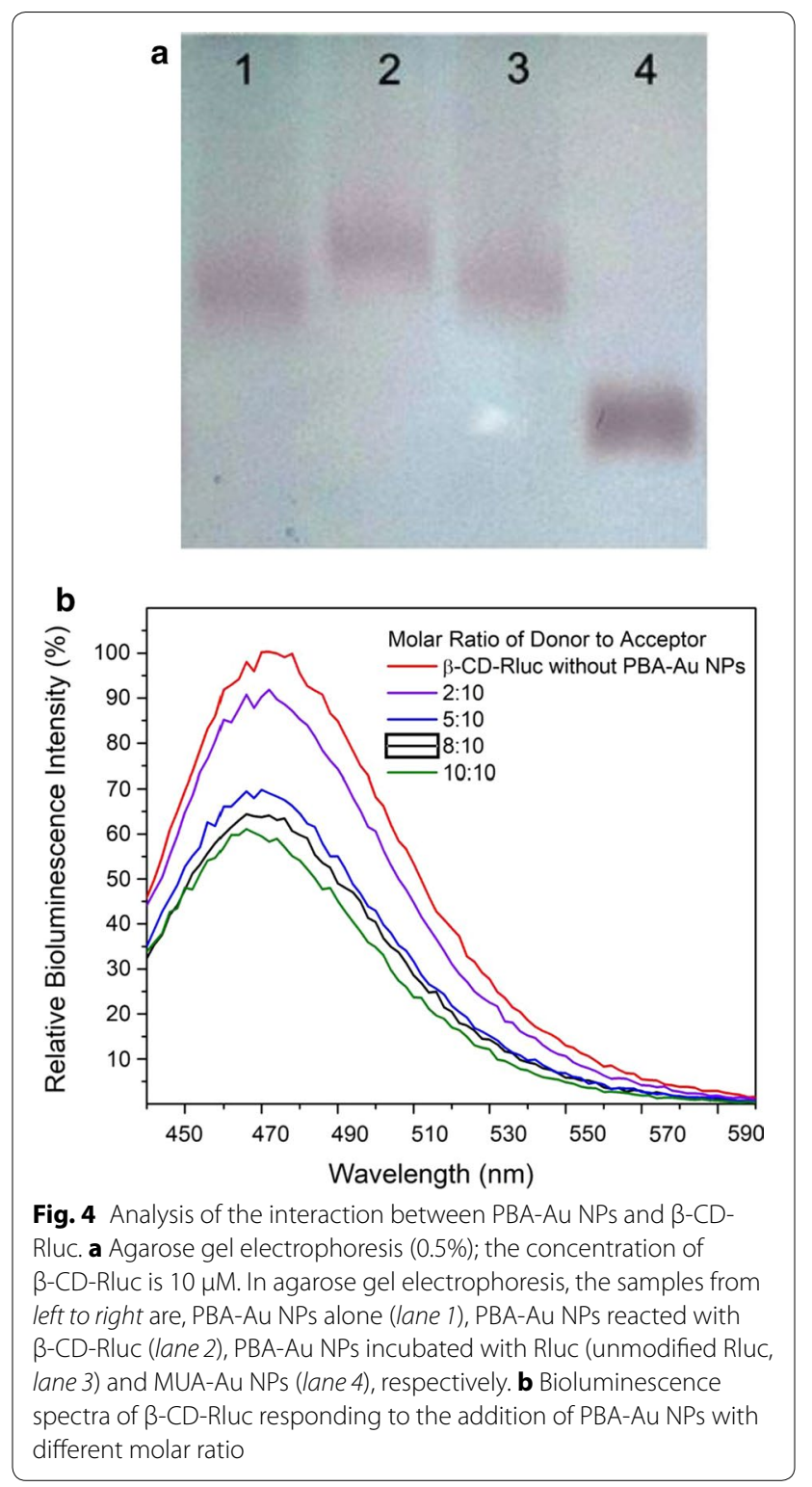

of Rluc is quenched by the conjugated Au NPs. Figure 4b shows that the bioluminescence intensity decreases gradually when adding more PBA-Au NPs in $\beta$-CD-Rluc by comparing to the signal from control group without NPs (red curve). The bioluminescence intensity can be quenched over $\sim 58 \%$ when the molar ratio of PBA-Au NPs to $\beta$-CD-Rluc in the mixture is increased to $10 / 10$ as shown in Fig. 4b.

Glucose intends to compete with $\beta$-CD-Rluc to react with PBA-Au NPs because the interaction between PBA and glucose is stronger than the reaction of $\beta-C D$ with PBA, which, therefore, results in the restore of bioluminescence as shown in Scheme 1. The bioluminescence intensity of $\beta-C D-R l u c$ as a function of the concentration 
of glucose was further investigated. In a typical assay, the nanostructured sensors (the molar ratio of NPs to protein $=10: 10$ )were mixed with glucose at different concentrations, respectively.. The mixtures were incubated for $30 \mathrm{~min}$. Figure 5 shows the bioluminescence intensity increases when the concentration of glucose in aqueous increases from 0 to $100 \mu \mathrm{M}$. It is noted that the positive control (PC) refers the $\beta$-CD-Rluc which has the same amount of $\beta$-CD-Rluc in the designed sensor.

The normalized bioluminescence intensity was calculated by using the Eq. 1;

$$
\begin{aligned}
& \text { Normalized Bioluminescence Intensity } \\
& =\frac{\text { Bioluminescence Intensity in the presence of glucose }}{\text { Bioluminescence Intensity of the positive control }}
\end{aligned}
$$

In addition, we tested the sensor performance with blood sample of diabetic rats to evaluate the interference of other proteins in blood. Figure 6 indicates the correlation between the normalized bioluminescence intensity and the $\log$ form of the concentration of glucose in aqueous samples and in diluted blood samples. The normalized bioluminescence intensity increases linearly when the logarithmic glucose concentration increases in a range from 1 to $100 \mu \mathrm{M}$ to both measurements in aqueous and in diluted blood samples as shown in Fig. 6 . The detection limit for this assay is secured to $1 \mu \mathrm{M}$ from three independent measurements. Meanwhile, the normalized bioluminescence intensity corresponding to the $\log$ form of glucose in blood samples is very close to the $\log$ form of glucose in aqueous sample. Consequently, this bioluminescence nanosensor can detect plasma glucose for diabetic rats.

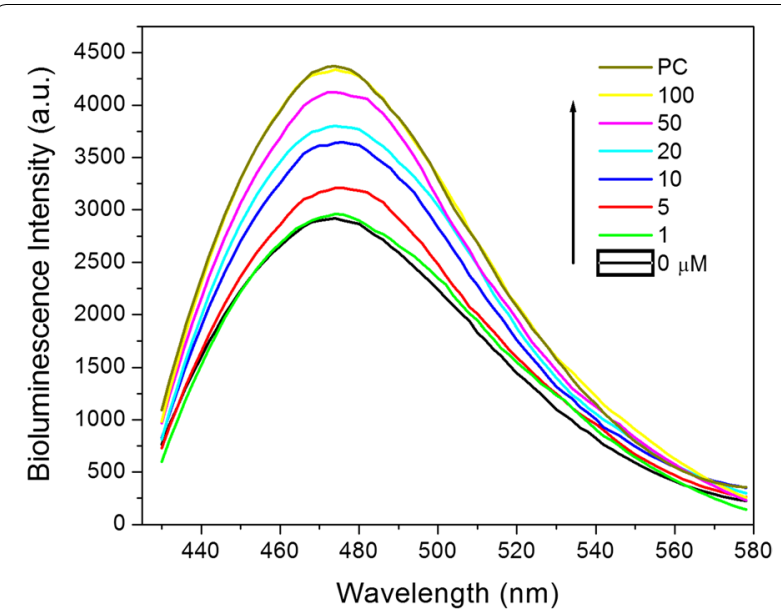

Fig. 5 Bioluminescence intensity with different glucose concentrations. PC refers the positive control, i.e. $\beta$-CD-Rluc alone without PBA-Au NPs

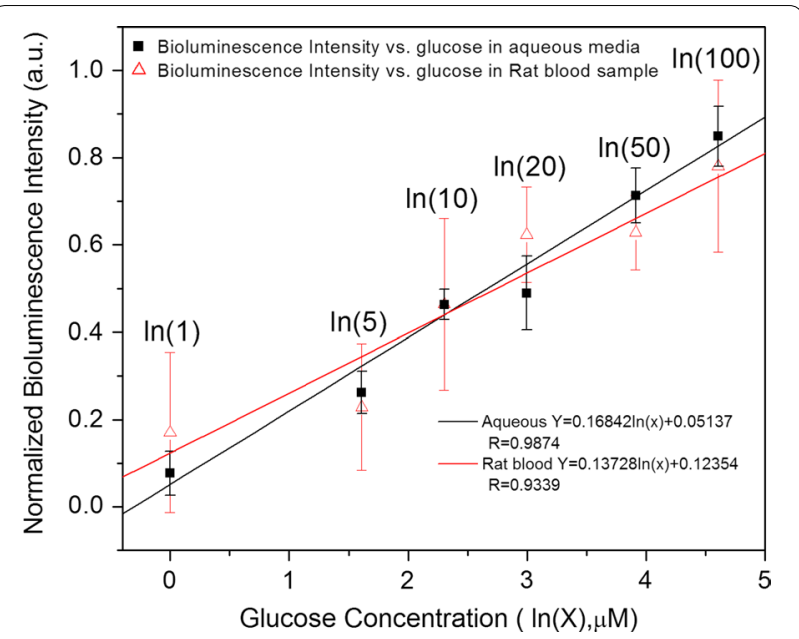

Fig. 6 Correlation between normalized bioluminescence intensity and the logarithmic glucose concentration in aqueous and in blood samples

\section{Discussions}

Bioluminescence reaction happens in nature when the enzyme, Rluc, reacts with a substrate, CTZ. We used the typical biological process to obtain pure and high amount of Rluc used as the donor in our designed BRET biosensor; first a plasmid containing Rluc gene was constructed, then the Rluc gene was cloned and expressed in bacterial system. High concentrated Rluc protein was obtained after the protein purification, and was conjugated to $\beta$-CD as shown in Fig. 1. Meanwhile, the acceptor was made by modified Au NPs which is able to quench the bioluminescence through the BRET mechanism. The particle size and size distribution were characterized by TEM and DLS as shown in Fig. 2 . The discrepancy of the results in size distribution may result from the surface modification of Au NPs by PBS which cannot be shown up on the TEM micrographs as organic molecules have very low electron density. The surface modification of Au NPs were studied and verified by FTIR as shown in Fig. 3. In the presence of glucose, the reaction of glucose with PBA competes against the reaction of $\beta-C D$ with $\mathrm{PBA}$, which leads to the release of Au NPs from Rluc and results in the restoration of the bioluminescence of Rluc as shown in Fig. 4. The maximum number of $\beta$-CD conjugated onto one Rluc is estimated at 10 as shown in the supplementary materials. Figure $4 \mathrm{~b}$ indicates that the bioluminescence intensity of Rluc can be quenched over $\sim 58 \%$ when the molar ratio of PBA-Au NPs to $\beta$-CD-Rluc in the mixture is increased to 10:10. The restoration of bioluminescence has a linear relationship with the logarithmic concentration of glucose in a range from 1 to $100 \mu \mathrm{M}$ as shown in Fig. 5. 
To further study the sensitivity and selectivity of the designed sensor, the glucose-specific detection was evaluated by investigating the response of restored bioluminescence intensity to different molecules. The results indicate that the bioluminescent sensor does not react with amino acids, lipids, and common sugars, i.e. mannose, lactose and maltose as shown in Additional file 1: Figure S2. However, sucrose and fructose exhibited higher reactivity to the nanostructured biosensor than glucose. This could be due to higher affinity constants of fructose to PBA than glucose [32, 33]. Meantime, as sucrose is a disaccharide composed of glucose and fructose units linked via their anomeric carbons, it could be expected that one or both monosaccharides could react with PBA-Au NPs.

Though high concentration of fructose may interfere the glucose detection by using the bioluminescent sensor, it should be noted that the concentration of fructose in human blood (both healthy and diabetes subjects) is very low, almost one thousand-fold lower than glucose concentration in healthy subject [34]. Meantime, sucrose is not commonly present in human blood in healthy subjects, as it is rapidly absorbed and hydrolyzed into its monosaccharide units in the small intestine [35, 36]. In addition, Fig. 6 indicates that the results of the blood measurement for diabetic rats is very close to the results of the glucose measurement in aqueous. It is noted that the serum levels of albumin, triglycerides, total protein and glucose in rats is compatible with human's. STZ induced diabetic rats have been well accepted as an animal model for diagnosis and treatment of diabetes [37, 38]. Consequently, this nanostructured sensor by applying the bioluminescence quenching technique can be used to detect glucose with a high sensitive and high selective fashion.

\section{Conclusions}

In conclusion, we have developed a new nanostructured biosensor by applying bioluminescence quenching technique for detecting glucose. Bioluminescent protein, Rluc, covalently conjugated with $\beta-C D$, is used as the donor in the designed biosensor, while PBA-Au NPs act as the acceptor. The PBA-Au NPs interacts $\beta$-CD-Rluc via a reversible covalent bonding results in the quenched bioluminescence of Rluc. In the presence of glucose, it competes with $\beta-C D$ to react with PBA, which releases $\mathrm{Au}$ NPs away from $\beta$-CD-Rluc, and results in the restoration of bioluminescence of Rluc. This paper also demonstrates the effect of the molar ratio of donor and acceptor on the bioluminescence quenching efficiency. The results indicate that normalized bioluminescence intensity increase linearly with increasing logarithmic glucose concentration in a range from 1 to $100 \mu \mathrm{M}$, with detection limit of $1 \mu \mathrm{M}$. This nanostructured bioluminescence quenching-based sensor could be feasible for blood glucose level monitoring with sample pre-treatment (e.g. dilution).

\section{Additional file}

Additional file 1: Figure S1. (a) Standard curve for sulfuric acid-pheno carbohydrate assay. (b) Calculated number of $\beta$-CD conjugated on Rluc after purification verse different molar ratios in the initial carbodiimide reactions. Figure S2. Response of bioluminescent nanosensors to common biological substances.

\section{Authors' contributions}

The study was planned by LC and JZ. LYC participated the experiments on materials characterization and data analysis. LYC and JZ worked with MD and $\mathrm{JM}$ on testing glucose level in rats' tears. MD and JM provided the STZ-induced diabetic rats. LC and JZ wrote the manuscript with input of all other coauthors. All authors read and approved the final manuscript.

\section{Author details}

${ }^{1}$ Department of Chemical and Biochemical Engineering, University of Western Ontario, 1151 Richmond St., London, ON N6A 5B9, Canada. ${ }^{2}$ School of Kinesiology, Faculty of Health Sciences, University of Western Ontario, London, ON N6A 5B9, Canada.

\section{Acknowledgements}

We are grateful for the financial support from the Natural Sciences and Engineering Research Council of Canada (NSERC).

\section{Competing interests}

The authors declare that they have no competing interests.

\section{Availability of data and materials}

All data generated or analyzed during this study are included in the article and the Additional file.

\section{Consent for publication}

Not applicable.

\section{Ethics approval and consent to participate}

Ethics approval was obtained through the University of Western Ontario Research Ethics Board, in accordance with Canadian Council on Animal Care guidelines.

Funding

This work was supported by the Natural Sciences and Engineering Research Council of Canada (NSERC).

\section{Publisher's Note}

Springer Nature remains neutral with regard to jurisdictional claims in published maps and institutional affiliations.

Received: 31 March 2017 Accepted: 10 August 2017

Published online: 22 August 2017

\section{References}

1. Guo X, Li H, Xu H, Woo S, Dong H, Lu F, Lange AJ, Wu C. Glycolysis in the control of blood glucose homeostasis. Acta Pharm Sin B. 2012;2:358-67.

2. Rahman MM, Ahammad AJS, Jin J-H, Ahn SJ, Lee J-J. a comprehensive review of glucose biosensors based on nanostructured metal-oxides. Sensors. 2010;10:4855.

3. Galant AL, Kaufman RC, Wilson JD. Glucose: detection and analysis. Food Chem. 2015;188:149-60. 
4. Özcan L, Şahin Y, Türk H. Non-enzymatic glucose biosensor based on overoxidized polypyrrole nanofiber electrode modified with cobalt(II) phthalocyanine tetrasulfonate. Biosens Bioelectron. 2008;24:512-7.

5. Yuan L, Lin W, Zheng K, Zhu S. FRET-based small-molecule fluorescent probes: rational design and bioimaging applications. Acc Chem Res. 2013;46:1462-73.

6. Shrestha S, Deo S. Bioluminescence resonance energy transfer in bioanalysis. In: Daunert S, Deo SK, editors. Photoproteins in bioanalysis. Weinheim: Wiley; 2006. p. 95-111.

7. Deuschle K, Chaudhuri B, Okumoto S, Lager I, Lalonde S, Frommer WB. Rapid metabolism of glucose detected with FRET glucose nanosensors in epidermal cells and intact roots of Arabidopsis RNA-silencing mutants. Plant Cell. 2006;18:2314-25.

8. So M-K, Loening AM, Gambhir SS, Rao J. Creating self-illuminating quantum dot conjugates. Nat Protoc. 2006;1:1160-4.

9. Johansson MK. Choosing reporter-quencher pairs for efficient quenching through formation of intramolecular dimers. In: Didenko WV, editor. Fluorescent energy transfer nucleic acid probes: designs and protocols. Totowa: Humana Press; 2006. p. 17-29.

10. Hoebe RA, Van Oven CH, Gadella TWJ, Dhonukshe PB, Van Noorden CJF, Manders EMM. Controlled light-exposure microscopy reduces photobleaching and phototoxicity in fluorescence live-cell imaging. Nat Biotech. 2007;25:249-53.

11. Pons T, Medintz IL, Sapsford KE, Higashiya S, Grimes AF, English DS, Mattoussi $\mathrm{H}$. On the quenching of semiconductor quantum dot photoluminescence by proximal gold nanoparticles. Nano Lett. 2007;7:3157-64.

12. Yun CS, Javier A, Jennings T, Fisher M, Hira S, Peterson S, Hopkins B, Reich NO, Strouse GF. Nanometal surface energy transfer in optical rulers, breaking the FRET barrier. J Am Chem Soc. 2005;127:3115-9.

13. Swierczewska M, Lee S, Chen X. The design and application of fluorophore-gold nanoparticle activatable probes. PCCP. 2011;13:9929-41.

14. Kim Y-P, Daniel WL, Xia Z, Xie H, Mirkin CA, Rao J. Bioluminescent nanosensors for protease detection based upon gold nanoparticleluciferase conjugates. Chem Commun. 2010;46:76-8.

15. Chen L, Bao Y, Denstedt J, Zhang J. Nanostructured bioluminescent sensor for rapidly detecting thrombin. Biosens Bioelectron. 2016;77:83-9.

16. Fan F, Binkowski BF, Butler BL, Stecha PF, Lewis MK, Wood KV. Novel genetically encoded biosensors using firefly luciferase. ACS Chem Biol. 2008;3:346-51.

17. Emonet SF, Garidou L, McGavern DB, de la Torre JC. Generation of recombinant lymphocytic choriomeningitis viruses with trisegmented genomes stably expressing two additional genes of interest. Proc Natl Acad Sci. 2009;106:3473-8.

18. Cai Y, Bak RO, Krogh LB, Staunstrup NH, Moldt B, Corydon TJ, Schrøder LD, Mikkelsen JG. DNA transposition by protein transduction of the piggyBac transposase from lentiviral Gag precursors. Nucleic Acids Res. 2014;42:e28.

19. Dragulescu-Andrasi A, Chan CT, De A, Massoud TF, Gambhir SS. Bioluminescence resonance energy transfer (BRET) imaging of protein-protein interactions within deep tissues of living subjects. Proc Natl Acad Sci. 2011;108:12060-5.

20. Mo X-L, Fu H. BRET: NanoLuc-based bioluminescence resonance energy transfer platform to monitor protein-protein interactions in live cells. In: Janzen WP, editor. High throughput screening: methods and protocols. New York: Springer New York; 2016. p. 263-71.
21. Ferrier RJ, Prasad D. 1360. Boric acid derivatives as reagents in carbohydrate chemistry. Part VI. Phenylboronic acid as a protecting group in disaccharide synthesis. J Chem Soc (Resumed). 1965;0:7429-7432. doi:10.1039/JR9650007429.

22. James TD, Sandanayake KRAS, Shinkai S. Saccharide sensing with molecular receptors based on boronic acid. Angew Chem Int Ed Engl. 1996;35:1910-22.

23. Wu Q, Wang L, Yu H, Wang J, Chen Z. Organization of glucose-responsive systems and their properties. Chem Rev. 2011;111:7855-75.

24. Hall DG. Boronic acids: preparation, applications in organic synthesis and medicine. Weinheim: Wiley; 2006.

25. Hames BD. Gel electrophoresis of proteins: a practical approach. Oxford: OUP Oxford; 1998.

26. Fairbridge RA, Willis KJ, Booth RG. The direct colorimetric estimation of reducing sugars and other reducing substances with tetrazolium salts. Biochem J. 1951;49:423-7.

27. DuBois M, Gilles KA, Hamilton JK, Rebers PA, Smith F. Colorimetric method for determination of sugars and related substances. Anal Chem. 1956;28:350-6.

28. Brinkley M. A brief survey of methods for preparing protein conjugates with dyes, haptens and crosslinking reagents. Bioconjugate Chem. 1992;3:2-13.

29. Jain PK, Qian W, El-Sayed MA. Ultrafast cooling of photoexcited electrons in gold nanoparticle - thiolated DNA conjugates involves the dissociation of the gold —-thiol bond. J Am Chem Soc. 2006;128:2426-33.

30. Brewer SH, Allen AM, Lappi SE, Chasse TL, Briggman KA, Gorman CB, Franzen S. Infrared detection of a phenylboronic acid terminated alkane thiol monolayer on gold surfaces. Langmuir. 2004;20:5512-20.

31. Timasheff SN, Fasman GD. Structure and stability of biological macromolecules. New York: Dekker; 1969.

32. Lorand JP, Edwards JO. Polyol complexes and structure of the benzeneboronate ion. J Org Chem. 1959;24:769-74.

33. Ayyub OB, Ibrahim MB, Briber RM, Kofinas P. Self-assembled block copolymer photonic crystal for selective fructose detection. Biosens Bioelectron. 2013;46:124-9.

34. Kawasaki T, Akanuma H, Yamanouchi T. Increased fructose concentrations in blood and urine in patients with diabetes. Diabetes Care. 2002;25:353-7.

35. Hewetson M, Cohen ND, Love S, Buddington RK, Holmes W, Innocent GT, Roussel AJ. Sucrose concentration in blood: a new method for assessment of gastric permeability in horses with gastric ulceration. J Vet Intern Med. 2006;20:388-94.

36. Sutherland LR, Verhoef $M$, Wallace $J$, van Rosendaal G, Crutcher R, Meddings JB. A simple, non-invasive marker of gastric damage: sucrose permeability. Lancet. 1994;343:998-1000.

37. Chen $L$, Chen LY, Tse WH, Chen Y, McDonald MW, Melling J, Zhang J. Nanostructured biosensor for detecting glucose in tear by applying fluorescence resonance energy transfer quenching mechanism. Biosens Bioelectron. 2017;2017(91):393-9.

38. Zhang DL, Luo G, Ding XX, Lu C. Preclinical experimental models of drug metabolism and disposition in drug discovery and development. Acta Pharmaceutica Sinica B. 2012;2(6):549-61.

\section{Submit your next manuscript to BioMed Central and we will help you at every step:}

- We accept pre-submission inquiries

- Our selector tool helps you to find the most relevant journal

- We provide round the clock customer support

- Convenient online submission

- Thorough peer review

- Inclusion in PubMed and all major indexing services

- Maximum visibility for your research

Submit your manuscript at www.biomedcentral.com/submit
() BioMed Central 